九州大学学術情報リポジトリ

Kyushu University Institutional Repository

\title{
A mechanism of photocatalytic and adsorptive treatment of 2,4-dinitrophenol on a porous thin film of Ti0_2 covering granular activated carbon particles
}

Cao, Xiangyu

Department of Bio-System Design, Bio-Architecture Center, Kyushu University

Shiraishi, Fumihide

Department of Bio-System Design, Bio-Architecture Center, Kyushu University

http://hdl. hand le. net/2324/26583

出版情報：Chemical Engineering Journal. 160 (2)，pp.651-659，2010-06-01. Elsevier バージョン：

権利関係: (C) 2010 Elsevier B.V. 


\title{
A mechanism of photocatalytic and adsorptive treatment of 2,4-dinitrophenol on a porous thin film of $\mathrm{TiO}_{2}$ covering granular activated carbon particles
}

\author{
Xiangyu Cao, Fumihide Shiraishi ${ }^{*}$ \\ Department of Bio-System Design, Bio-Architecture Center, Kyushu University, 6-10-1,
} Hakozaki, Higashi-ku, Fukuoka, 812-0036, Japan.

* Corresponding author: Tel. \& Fax.: +92 6427603.

E-mail address: fumishira@brs.kyushu-u.ac.jp (F. Shiraishi). 


\section{Abstract}

The present work investigates the mechanism of the photocatalytic and adsorptive treatment of an aqueous DNP (2,4-dinitrophenol) solution in an annular-flow reactor installed with a $\mathrm{TiO}_{2} / \mathrm{AC}-\mathrm{PET}$ film (a polyethylene terephthalate film adhesively fixing activated carbon particles covered with a thin and porous film of titanium dioxide). Unfortunately, the experimental result indicates that it is impossible to correctly measure the time courses of product ion concentrations because they are adsorbed onto or desorbed from AC particles. Therefore, a computer simulation methodology using mathematical models is introduced in order to elucidate the treatment mechanism. Treatments of aqueous DNP solutions using the $\mathrm{TiO}_{2}$-PET film reveal that the diffusion of DNP from a bulk solution to a $\mathrm{TiO}_{2}$ film is based on the gradient of DNP concentration, generated by a rapid adsorption of DNP onto AC and photocatalytic reaction, in the very neighborhood of $\mathrm{TiO}_{2}$ film, and this diffusion increases the DNP concentration at the surface of $\mathrm{TiO}_{2}$ film, thereby enhancing the rate of photocatalytic decomposition. Moreover, it is found that the $\mathrm{TiO}_{2} / \mathrm{AC}$-PET film can lower the burden of the adsorption of DNP onto AC compared with the AC-PET film because a part of DNP molecules are photocatalytically decomposed and the percentage of this decomposition is increased at a lower linear velocity. In conclusion, the mathematical 
model taking into consideration a film-diffusional effect can successfully explain the complicated mechanism of the treatment of an aqueous DNP solution using the $\mathrm{TiO}_{2} / \mathrm{AC}-\mathrm{PET}$ film.

Keywords: Photocatalytic reaction, Adsorption, Activated carbon, Diffusion, Mathematical models, Effectiveness factor, Partition 


\section{Introduction}

A number of wastewaters containing various kinds of organic compounds are treated by microbial decomposition processes. When the wastewaters contain organic compounds highly toxic to microbial cells, however, introduction of some other method must be considered [1-4]. For example, wastewaters containing 2,4-dinitrophenol (DNP), which is mainly used as a raw material of black dyes, polymerization inhibitor, and wood preservative, significantly restrict cell growth even when the DNP concentration level is of the order of $1 \mathrm{ppm}$ (parts per million). According to the PRTR (Pollutant Release and Transfer Register) data in 2007, it is estimated that DNP of about 0.38 tons per year was released into the environment in Japan[5].

Titanium dioxide $\left(\mathrm{TiO}_{2}\right)$ irradiated with UV light can decompose a wide variety of organic compounds to carbon dioxide, water, and mineral acids or their salts $[3,6,7]$. Hence, the decomposition method using $\mathrm{TiO}_{2}$ has a potential for the treatment of wastewaters containing toxic organic compounds such as DNP [1, 2, 4, 8-10]. Unfortunately, it is not easy to enhance the rate of photocatalytic decomposition to a level of practical application because $\mathrm{TiO}_{2}$ does not sufficiently adsorb organic compounds, especially when they are hydrophobic.

To solve this problem, many researchers have attempted to combine $\mathrm{TiO}_{2}$ with 
adsorptive materials such as activated carbon (AC) and zeolite particles [4, 11-14]. A high photocatalytic activity may be achieved if the surface area of $\mathrm{TiO}_{2}$ per unit volume is successfully increased. One of the best ways is to completely cover the surface of adsorptive materials with a $\mathrm{TiO}_{2}$ film in order to get as much field for the photocatalytic reaction as possible. In this case, however, the adsorption ability of AC particles can not be utilized efficiently.

In a previous work[15], we prepared a $\mathrm{TiO}_{2} / \mathrm{AC}-\mathrm{PET}$ film, where the surface of $\mathrm{AC}$ particles adhesively fixed onto a PET film was completely covered with a porous and thin film of $\mathrm{TiO}_{2}$ crystal particles in large sizes, and investigated its performance for the treatment of an aqueous DNP solution. As a result, we found that the $\mathrm{TiO}_{2} / \mathrm{AC}$-PET film can rapidly treat it compared to a $\mathrm{TiO}_{2}$-PET film where the $\mathrm{TiO}_{2}$ particles were directly loaded onto a PET film. Interestingly, in this reaction system, the rate of a decrease in the DNP concentration by the $\mathrm{TiO}_{2} / \mathrm{AC}$-PET film without UV irradiation was almost the same as that by the AC-PET film. This finding implies that the adsorption ability of AC is not weaken in the presence of the $\mathrm{TiO}_{2}$ film because it is very thin and porous. In addition, the $\mathrm{TiO}_{2} / \mathrm{AC}-\mathrm{PET}$ film was able to treat a 1.8 times larger amount of DNP than did the AC-PET film until AC on each PET film was saturated with DNP. This experimental fact suggests that DNP may be decomposed at a higher reaction rate by the 
$\mathrm{TiO}_{2}$ /AC-PET film than by the $\mathrm{TiO}_{2}$-PET film, because the DNP concentration on the $\mathrm{TiO}_{2}$ /AC-PET film would be more increased by a high attraction force of AC; consequently, the burden of AC adsorption of DNP is lowered and a larger amount of DNP can be treated by the $\mathrm{TiO}_{2} / \mathrm{AC}-\mathrm{PET}$ film than by the AC-PET film.

The purpose of the present work is to elucidate the mechanism of the photocatalytic and adsorptive treatment of DNP using the $\mathrm{TiO}_{2} / \mathrm{AC}$-PET film. To achieve this purpose, the scheme of the photocatalytic decomposition of DNP is firstly investigated on the basis of the decomposition experiment using the $\mathrm{TiO}_{2}$-PET film. Secondly, the treatment of DNP using the $\mathrm{TiO}_{2}$ /AC-PET film is experimentally analyzed, which indicates that there is a limitation to experimental elucidation of its mechanism. Therefore, mathematical models are constructed to theoretically elucidate the mechanism of the photocatalytic and adsorptive treatment.

\section{Experimental method}

\subsection{Materials}

DNP used as a reactant was purchased from Wako Pure Chemical Industries, Ltd.

(Osaka, Japan). A nonionic surfactant (polyoxyethylene lauryl ether with a degree of polymerization of 23) used to increase the affinity of an aqueous $\mathrm{TiO}_{2}$ coating solution 
to a PET film was also the product of Wako Pure Chemical Industries, Ltd. The coating solution (aqueous $\mathrm{H}_{2} \mathrm{O}_{2}$ solution) containing anatase $\mathrm{TiO}_{2}$ fine particle in sizes of 10-25 $\mu \mathrm{m}$ was a product of Sundecor Co. Ltd. (Fukuoka, Japan). The details of this coating solution are described elsewhere[16]. A 6-W blacklight blue fluorescent lamp (Matsushita Electric Industrial Co., Ltd., Osaka, Japan; FL6BL-B) was used as a light source of UV light (wavelengths; 300-400nm). Granular AC particles in sizes of roughly 1-2 mm were purchased from Japan EnviroChemicals Ltd. (WH2CSS; Osaka, Japan).

\subsection{Preparations of $\mathrm{TiO}_{2}-, \mathrm{AC}$ - and $\mathrm{TiO}_{2} / \mathrm{AC}$-PET films}

Polyethylene terephthalate (PET) films, $0.085 \times 0.195 \mathrm{~m}$ in size and $0.01 \mathrm{~mm}$ thick, were used as supports of $\mathrm{TiO}_{2}, \mathrm{AC}$ and $\mathrm{AC}$ coated with $\mathrm{TiO}_{2}$. The preparation methods are detailed elsewhere [15]. In the following, the PET film covered with a thin film of $\mathrm{TiO}_{2}$ is referred to as $\mathrm{TiO}_{2}$-PET film, the PET film where AC particles are adhesively fixed onto its surface is referred to as AC-PET film, and the PET-film where the surface of the AC particles adhesively fixed is completely covered with a thin film of $\mathrm{TiO}_{2}$ is referred to as $\mathrm{TiO}_{2} /$ AC-PET film. The weights of $\mathrm{TiO}_{2}$ loaded on $\mathrm{TiO}_{2^{-}}$and $\mathrm{TiO}_{2}$ /AC-PET films were determined to be about 0.09 and $0.12 \mathrm{~g}$, respectively. 
However, since the measured weight for the $\mathrm{TiO}_{2} / \mathrm{AC}$-PET film includes the weight of water absorbed into AC particles, we consider that there is not remarkable difference between the amounts of $\mathrm{TiO}_{2}$ loaded on the $\mathrm{TiO}_{2}$ - and $\mathrm{TiO}_{2} /$ AC-PET films.

\subsection{Experimental procedures}

The removal experiments of DNP from aqueous solutions were conducted in a batch-recirculation system with an annular-flow photocatalytic reactor [17-21] as shown in Fig. 1. The plastic photocatalytic reactor consists of a cylindrical vessel $(0.20 \mathrm{~m}$ long and $0.0285 \mathrm{~m}$ in inlet diameter), a 6-W blacklight blue fluorescent lamp, a quartz glass tube $(0.024 \mathrm{~m}$ in outer diameter $)$ used for protection of the UV lamp, and a PET film with $\mathrm{TiO}_{2}$ and/or $\mathrm{AC}$ particles. The photocatalytic reactor was connected with a mixed-flow container via a peristaltic pump (RP-2; EYELA, Tokyo, Japan) as shown in Fig.1. A reaction mixture flows through an annulus between the inside wall of the cylindrical vessel and the outside wall of the quartz glass tube. The PET film was inserted into the annulus so that it contacts closely to the inside wall of the cylindrical vessel. The volume of the annulus in the photocatalytic reaction zone was $3.7 \times 10^{-5} \mathrm{~m}^{3}$.

A $5.0 \times 10^{-4} \mathrm{~m}^{3}$ aqueous solution of DNP at different initial concentrations was poured into the mixed-flow container and then circulated at different flow rates. The UV 
lamp was switched on to start the photocatalytic reaction. At appropriate time intervals, an aliquot of the reaction mixture in the mixed-flow container was withdrawn to determine the DNP concentration by measurement of an absorbance at $357 \mathrm{~nm}$ with a spectrophotometer (Ultrospec 1100Pro; Amersham Biosciences, Sweden). The concentrations of ions $\left(\mathrm{NO}_{2}^{-}, \mathrm{NO}_{3}{ }^{-}, \mathrm{NH}_{4}{ }^{+}\right.$, and $\left.\mathrm{CO}_{3}{ }^{2-}\right)$ produced during the DNP decomposition were determined by ion chromatography (ICS 90; Japan Dionex, Osaka, Japan).

\section{Mathematical models}

\subsection{Constitution of reaction systems and characteristics of experimental data}

The present work treats DNP solutions in a batch-recirculation mode. That is, a reaction mixture of the volume $V_{\mathrm{L}}$ in a mixed-flow container is circulated by passing through an annular-flow photocatalytic reactor. The rate of recirculation is very large compared to the rate of decomposition (the rate of treatment). Therefore, the present treatment can be approximately regarded as a batch mode, which means that the reactant concentration profile along the reactor can be neglected $[22,23]$. On the other hand, the experimental data given in a previous paper [15] possess the following characteristics.

1) There is no significant difference between the time courses of DNP 
concentrations in bulk solutions in the treatments of aqueous DNP solutions using the $\mathrm{TiO}_{2} / \mathrm{AC}-\mathrm{PET}$ film without UV irradiation and the AC-PET film. This means that the thin film of $\mathrm{TiO}_{2}$ covering the surface of $\mathrm{AC}$ particles on the $\mathrm{TiO}_{2} / \mathrm{AC}-\mathrm{PET}$ film hardly lowers the ability of AC to attract DNP.

2) In repeated treatments of aqueous DNP solutions, the amount of DNP required to saturate the $\mathrm{AC}$ on the $\mathrm{TiO}_{2} / \mathrm{AC}-\mathrm{PET}$ is 1.8 times larger than that on the AC-PET film. This means that the burden of the adsorption of DNP on AC is lowered as a result of photocatalytic decomposition of DNP.

The mathematical models to be constructed must be satisfied with these facts.

\subsection{Mathematical model for decomposition of DNP using a $\mathrm{TiO}_{2}$-PET film}

In the batch-recirculation annular-flow reactor installed with a $\mathrm{TiO}_{2}$-PET film, reactant molecules diffuse through a liquid film from a bulk solution to a photocatalyst surface excited with UV light and are then decomposed photocatalytically. The present system is kept at a steady state and the flux of reactant molecules diffusing through the liquid film is equal to the rate of decomposition on the $\mathrm{TiO}_{2}$ film. Thus, a differential mass balance gives

$$
-V_{\mathrm{L}} \frac{\mathrm{d} C_{\mathrm{b}}}{\mathrm{d} t}=k_{\mathrm{Lp}} A_{\mathrm{s}}\left(C_{\mathrm{b}}-C_{\mathrm{p}}\right)
$$




$$
V_{\mathrm{P}} \frac{\mathrm{d} C_{\mathrm{p}}}{\mathrm{d} t}=k_{\mathrm{Lp}} A_{\mathrm{s}}\left(C_{\mathrm{b}}-C_{\mathrm{p}}\right)-\frac{k_{\mathrm{p}} V_{\mathrm{p}} K_{\mathrm{H}} C_{\mathrm{p}}}{1+K_{\mathrm{H}} C_{\mathrm{p}}}=0
$$

with the initial conditions:

$$
C_{\mathrm{b}}=C_{\mathrm{b} 0}, C_{\mathrm{p}}=C_{\mathrm{p} 0}=0 \quad \text { at } \quad t=0
$$

where $k_{\mathrm{p}}\left[\mathrm{mmol} \mathrm{m} \mathrm{m}^{-3}\right.$-cat $\left.\mathrm{min}^{-1}\right]$ is the rate constant of the photocatalytic decomposition, $K_{\mathrm{H}}\left[\mathrm{mmol}^{-1} \mathrm{~m}^{3}\right]$ is the adsorption equilibrium constant, $C_{\mathrm{p}}\left[\mathrm{mmol} \mathrm{m}{ }^{-3}\right]$ is the DNP concentration at the $\mathrm{TiO}_{2}$ surface, $k_{\mathrm{Lp}}\left[\mathrm{m} \mathrm{min}^{-1}\right]$ is the mass-transfer coefficient for the diffusion of DNP through a liquid film in the photocatalytic reaction system, $C_{\mathrm{b}}[\mathrm{mmol}$ $\left.\mathrm{m}^{-3}\right]$ is the DNP concentration in a bulk solution, $V_{\mathrm{L}}\left[\mathrm{m}^{3}\right]$ is the volume of a reaction mixture, $A_{\mathrm{s}}\left[\mathrm{m}^{2}\right.$-cat $]$ is the area of a plane perpendicular to the direction of diffusion, $V_{\mathrm{p}}$ [ $\mathrm{m}^{3}$-cat] is the volume of the $\mathrm{TiO}_{2}$ film, and $t$ [min] is the reaction time. Also, the subscript "0" represents the value at $t=0$, namely, the initial value. Solving Eq. (2) with respect to $C_{\mathrm{p}}$ and substituting the obtained equation into Eq. (1) gives a differential equation that is a function of only $C_{\mathrm{b}}$. The time course of $C_{\mathrm{b}}$ is obtained by numerically solving this differential equation. If there is no film-diffusional resistance, i.e., if $k_{\mathrm{Lp}}=\infty$, Eqs. (1) and (2) is simplified to the following kinetic equation:

$$
v_{\mathrm{p}}=-\frac{\mathrm{d} C_{\mathrm{b}}}{\mathrm{d} t}=\frac{\left(k_{\mathrm{p}} / V_{\mathrm{L}}\right) V_{\mathrm{P}} K_{\mathrm{H}} C_{\mathrm{b}}}{1+K_{\mathrm{H}} C_{\mathrm{b}}}
$$

with the initial condition:

$$
C_{\mathrm{b}}=C_{\mathrm{b} 0} \text { at } t=0 .
$$


where $v_{\mathrm{p}}\left[\mathrm{mmol} \mathrm{m} \mathrm{min}^{-1}\right]$ is the photocatalytic reaction rate. The values of $k_{\mathrm{p}}$ and $K_{\mathrm{H}}$ are determined from a linearized plot based on the initial rates of decomposition $v_{\mathrm{p} 0}$ measured at various initial reactant concentrations $C_{\mathrm{b} 0}$.

\subsection{Mathematical model for adsorption of DNP onto an AC-PET film}

In the batch-recirculation annular-flow reactor installed with an AC-PET film, the DNP concentration is decreased as a result of AC adsorption of DNP. A differential mass balance gives [24]

$$
-V_{\mathrm{L}} \frac{\mathrm{d} C_{\mathrm{b}}}{\mathrm{d} t}=k_{\mathrm{La}} A_{\mathrm{s}}\left(C_{\mathrm{b}}-C_{\mathrm{a}} e^{\lambda_{\mathrm{a}}}\right)=V_{\mathrm{a}} \frac{\mathrm{d} C_{\mathrm{a}}}{\mathrm{d} t}
$$

with the initial conditions:

$$
C_{\mathrm{b}}=C_{\mathrm{b} 0}, C_{\mathrm{a}}=C_{\mathrm{a} 0}=0 \quad \text { at } t=0
$$

where $C_{\mathrm{a}}\left[\mathrm{mmol} \mathrm{m} \mathrm{m}^{-3}\right]$ is the DNP concentration on AC particles, $k_{\mathrm{La}}\left[\mathrm{m} \mathrm{min}^{-1}\right]$ is the mass-transfer coefficient for the diffusion of DNP through a liquid film in the AC adsorption system, $\lambda_{\mathrm{a}}[-]$ is the partition coefficient for DNP at the surface of AC particles, and $V_{\mathrm{a}}\left[\mathrm{m}^{3}\right]$ is the volume of AC particles. In general, it may be possible to express $k_{\mathrm{La}}$ and $k_{\mathrm{Lp}}$ in terms of the same mass transfer coefficient. However, the surface condition of the $\mathrm{TiO}_{2}-$ and $\mathrm{TiO}_{2} /$ AC-PET films are markedly different, which would give subtle differences in the thicknesses of diffusion film and the surface areas for 
diffusion. For simplification, therefore, the present work distinguishes and sets up them as different mass transfer coefficients. Equation (4) provides the following equation expressing a relationship between $C_{\mathrm{a}}$ and $C_{\mathrm{b}}$.

$$
C_{\mathrm{a}}=\left(V_{\mathrm{L}} / V_{\mathrm{a}}\right)\left(C_{\mathrm{b} 0}-C_{\mathrm{b}}\right)
$$

Substitution of Eq. (5) into Eq. (4) gives

$$
\frac{\mathrm{d} C_{\mathrm{b}}}{\mathrm{d} t}+\frac{k_{\mathrm{La}} A_{\mathrm{s}}}{V_{\mathrm{L}}}\left(1+\frac{V_{\mathrm{L}} e^{\lambda_{\mathrm{a}}}}{V_{\mathrm{a}}}\right) C_{\mathrm{b}}=\frac{k_{\mathrm{La}} A_{\mathrm{s}} e^{\lambda_{\mathrm{a}}}}{V_{\mathrm{a}}} C_{\mathrm{b} 0} .
$$

Equation (6) is a linear first-order differential equation, whose analytical solution leads to

$$
C_{\mathrm{b}}=C_{\mathrm{b} 0}\left(\frac{V_{\mathrm{a}}}{V_{\mathrm{a}}+V_{\mathrm{L}} e^{\lambda_{\mathrm{a}}}}\right) \exp \left[-\frac{k_{\mathrm{La}} A_{\mathrm{s}}\left(V_{\mathrm{a}}+V_{\mathrm{L}} e^{\lambda_{\mathrm{a}}}\right)}{V_{\mathrm{a}} V_{\mathrm{L}}} t\right]+C_{\mathrm{b}, \mathrm{eq}}
$$

where

$$
C_{\mathrm{b}, \mathrm{eq}}=\frac{C_{\mathrm{b} 0} V_{\mathrm{L}} e^{\lambda_{\mathrm{a}}}}{V_{\mathrm{a}}+V_{\mathrm{L}} e^{\lambda_{\mathrm{a}}}}
$$

Firstly, the final reactant concentrations in a bulk solution, i.e., equilibrium reactant concentrations, $C_{\mathrm{b} \text {,eq }}$, must be obtained from the time course data of $C_{\mathrm{b}}$ in the treatments of aqueous DNP solutions at different values of $C_{\mathrm{b} 0}$. Secondly, the values of $C_{\mathrm{b} \text {,eq }}$ are plotted against the values of $C_{\mathrm{b} 0}$ to obtain the value of $\lambda_{\mathrm{a}}$ from the slope of the linear plot of Eq. (8). Finally, $k_{\mathrm{La}}$ is determined so that the calculated result by Eq. (7) agrees with the time course data of $C_{\mathrm{b}}$. 
3.4 Mathematical model for adsorption and decomposition of DNP on a $\mathrm{TiO}_{2}$ /AC-PET film

The $\mathrm{TiO}_{2}$ /AC-PET film is set in the annular-flow reactor to treat an aqueous solution containing DNP in the batch-recirculation flow system. The $\mathrm{TiO}_{2}$ film covering the surface of AC particles hardly lowers the ability of AC particles to attract DNP, because it is thin and porous. The DNP concentration in the very neighborhood of the $\mathrm{TiO}_{2} / \mathrm{AC}-\mathrm{PET}$ film is significantly reduced due to a rapid adsorption of DNP onto AC and its photocatalytic decomposition, so that the DNP molecules can quickly diffuse to the neighborhood of the PET film by utilization of a large concentration gradient as a driving force. The DNP concentration at the $\mathrm{TiO}_{2}$ film is higher than that in its neighbourhood because of solid-liquid partition. About half of the DNP molecules on the $\mathrm{TiO}_{2}$ film would be photocatalytically decomposed and the others would be quickly attracted and adsorbed onto AC. The DNP concentration at the $\mathrm{TiO}_{2}$ film is higher with $\mathrm{TiO}_{2} / \mathrm{AC}-\mathrm{PET}$ film than with $\mathrm{TiO}_{2}$-PET film because the flux of DNP passing through the porous $\mathrm{TiO}_{2}$ film becomes larger as a result of quick attraction of DNP by AC. This in turn increases the rate of photocatalytic decomposition of DNP. Not only undecomposed DNP molecules but also a part of intermediates produced by DNP decomposition are adsorbed on AC. This series of process including diffusion, partition, 
photocatalytic decomposition, and $\mathrm{AC}$ adsorption is described as follows;

$$
\begin{aligned}
& -V_{\mathrm{L}} \frac{\mathrm{d} C_{\mathrm{b}}}{\mathrm{d} t}=k_{\mathrm{La}} A_{\mathrm{s}}\left(C_{\mathrm{b}}-C_{\mathrm{p}} e^{\lambda_{\mathrm{p}}}\right)+k_{\mathrm{La}} A_{\mathrm{s}}\left(C_{\mathrm{b}}-C_{\mathrm{a}} e^{\lambda_{\mathrm{a}}}\right) \\
& V_{\mathrm{p}} \frac{\mathrm{d} C_{\mathrm{p}}}{\mathrm{d} t}=k_{\mathrm{La}} A_{\mathrm{s}}\left(C_{\mathrm{b}}-C_{\mathrm{p}} e^{\lambda_{\mathrm{p}}}\right)-\frac{k_{\mathrm{p}} V_{\mathrm{p}} K_{\mathrm{H}} C_{\mathrm{p}}}{1+K_{\mathrm{H}} C_{\mathrm{p}}} \\
& V_{\mathrm{a}} \frac{\mathrm{d} C_{\mathrm{a}}}{\mathrm{d} t}=k_{\mathrm{La}} A_{\mathrm{s}}\left(C_{\mathrm{b}}-C_{\mathrm{a}} e^{\lambda_{\mathrm{a}}}\right)
\end{aligned}
$$

with the initial conditions:

$$
C_{\mathrm{b}}=C_{\mathrm{b} 0}, C_{\mathrm{p}}=C_{\mathrm{p} 0}=0, C_{\mathrm{a}}=C_{\mathrm{a} 0}=0 \text { at } t=0
$$

where $\lambda_{\mathrm{p}}[-]$ is the partition coefficient for $\mathrm{DNP}$ at the $\mathrm{TiO}_{2}$ film. Equations (9) to (11) simply describe an increase in the DNP concentration in the neighbourhood of the $\mathrm{TiO}_{2}$ film, which is caused by the adsorption ability of $\mathrm{AC}$, in terms of a partition phenomenon.

\subsection{Catalytic effectiveness factor}

The catalytic effectiveness factor, $E_{f}$ in a photocatalytic reaction system is

written as $[17,18]$

$$
\begin{aligned}
E_{\mathrm{f}}= & \frac{\text { Actual rate of decomposition }}{\text { Ideal rate of decomposition in absence of }} \\
& \begin{array}{c}
\text { diffusional resistance } \\
=
\end{array} \\
& \frac{v_{\mathrm{p}}\left(C_{\mathrm{p}}\right)}{v_{\mathrm{p}}\left(C_{\mathrm{b}}\right)}=\frac{V_{\mathrm{p}} K_{\mathrm{H}} C_{\mathrm{p}} /\left(1+K_{\mathrm{H}} C_{\mathrm{p}}\right)}{V_{\mathrm{p}} K_{\mathrm{H}} C_{\mathrm{b}} /\left(1+K_{\mathrm{H}} C_{\mathrm{b}}\right)}=\frac{\beta_{\mathrm{p}} /\left(1+\beta_{\mathrm{p}}\right)}{\beta_{\mathrm{b}} /\left(1+\beta_{\mathrm{b}}\right)} .
\end{aligned}
$$

Equation (2) gives the following equation for the dimensionless DNP 
concentration at the $\mathrm{TiO}_{2}$ surface:

$$
\beta_{\mathrm{p}}=\frac{-\left(\phi+1-\beta_{\mathrm{b}}\right)+\sqrt{\left(\phi+1-\beta_{\mathrm{b}}\right)^{2}+4 \beta_{\mathrm{b}}}}{2}
$$

where $\beta_{\mathrm{p}}=C_{\mathrm{p}} K_{\mathrm{H}}, \beta_{\mathrm{b}}=C_{\mathrm{b}} K_{\mathrm{H}}$, and $\phi=k_{\mathrm{p}} V_{\mathrm{p}} K_{\mathrm{H}} /\left(k_{\mathrm{Lp}} A_{\mathrm{s}}\right)$. Application of Eq. (13) to Eq. (12) gives the equation of $E_{f}$ as

$$
E_{\mathrm{f}}=\frac{\left(\beta_{\mathrm{b}}+1\right)\left\{\beta_{\mathrm{b}}+\phi+1-\sqrt{\left(\phi+1-\beta_{\mathrm{b}}\right)^{2}+4 \beta_{\mathrm{b}}}\right\}}{2 \phi \beta_{\mathrm{b}}} .
$$

Consequently, the rate of decomposition of DNP for the $\mathrm{TiO}_{2}-\mathrm{PET}$ film is described as

$$
v_{\mathrm{p}}=-\frac{\mathrm{d} C_{\mathrm{b}}}{\mathrm{d} t}=E_{\mathrm{f}} \frac{\left(k_{\mathrm{p}} / V_{\mathrm{L}}\right) V_{\mathrm{p}} K_{\mathrm{H}} C_{\mathrm{b}}}{1+K_{\mathrm{H}} C_{\mathrm{b}}}
$$

\subsection{Mass-transfer coefficient}

In general, the mass-transfer coefficient $k_{\mathrm{L}}$ is expressed as a function of the linear

velocity $u$ for a reaction mixture passing through the inside of a photocatalytic reactor,

given $[18,25,26]$ by

$$
k_{\mathrm{L}}=a u^{b}
$$

where $a$ and $b$ are the experimental constants determined from the initial rates of treatments based on the time courses of the DNP concentrations in the treatments of aqueous DNP solutions at a constant concentration under different conditions of linear velocity. The determination method of $a$ and $b$ is described elsewhere $[18,25]$.

\section{Results and discussion}




\subsection{Decomposition of DNP using a TiO ${ }_{2}$-PET film}

A $0.5 \times 10^{-4} \mathrm{~m}^{3}$ aqueous solution of DNP at an initial concentration of $57.6 \mathrm{mmol} \mathrm{m}^{-3}$ was treated using the annular-flow reactor installed with a $\mathrm{TiO}_{2}$-PET film at a linear velocity of $0.55 \mathrm{~m} \mathrm{~min}^{-1}$. Figure 2 shows the time courses of $\mathrm{DNP}, \mathrm{CO}_{3}{ }^{2-}, \mathrm{NO}_{2}^{-} \mathrm{NH}_{4}^{+}$, and $\mathrm{NO}_{3}{ }^{-}$concentrations in this treatment. No photolysis of DNP was found under irradiation with UV light from the blacklight blue fluorescent lamp. The DNP concentration decreased to an almost zero value in $8 \mathrm{~h}$. At the same time, the $\mathrm{NO}_{3}{ }^{-}$ concentration increased quickly and reached a value over $70 \mathrm{mmol} \mathrm{m}^{-3}$ after $24 \mathrm{~h}$. The $\mathrm{NO}_{2}{ }^{-}$concentration initially increased, passing through a maximum at about $2 \mathrm{~h}$ and decreasing to an almost zero value after $8 \mathrm{~h}$. This behaviour suggests that $\mathrm{NO}_{2}^{-}$is an intermediate in a consecutive decomposition reaction. $\mathrm{The}^{\mathrm{NH}_{4}}{ }^{+}$concentration quickly increased until $4 \mathrm{~h}$, reaching its maximum and then staying at the neighbourhood of its value. The $\mathrm{CO}_{3}{ }^{2-}$ concentration stayed at an almost zero value until $6 \mathrm{~h}$, increasing and taking a constant value of about $10 \mathrm{mmol} \mathrm{m}$ after $24 \mathrm{~h}$. This result suggests slow decompositions of intermediates produced from DNP.

Consequently, the photocatalytic decomposition of DNP is estimated to occur according to the reaction mechanism shown in Fig. 3. The fundamental of this reaction mechanism was proposed by Nakano et al. [4]. The reaction mechanism in Fig. 3 is a 
combination of their mechanism with our experimental results that nitro groups are quickly eliminated from DNP, while intermediates produced from DNP are slowly decomposed to $\mathrm{CO}_{3}{ }^{2-}$.

\subsection{Effect of ions adsorbed on a $\mathrm{TiO}_{2} / \mathrm{AC}$-PET film}

A $0.5 \times 10^{-4} \mathrm{~m}^{3}$ aqueous solution, containing $\mathrm{NO}_{3}{ }^{-}, \mathrm{NO}_{2}{ }^{-}, \mathrm{CO}_{3}{ }^{2-}$ and $\mathrm{NH}_{4}{ }^{+}$at initial concentrations of $14.1,13.3,37.5$, and $5.5 \mathrm{mmol} \mathrm{m}^{-3}$, respectively, was treated using $5 \mathrm{~g}$ of suspended fresh granular AC particles under vigorous mixing for $2 \mathrm{~h}$. The experimental result suggested that the fresh $\mathrm{AC}$ particles originally contain $\mathrm{CO}_{3}{ }^{2-}$ and $\mathrm{NH}_{4}{ }^{+}$(especially contain $\mathrm{CO}_{3}{ }^{2-}$ in large amounts) and these ions may be solved out into the liquid solution during the DNP treatment. On the other hand, $\mathrm{NO}_{3}{ }^{-}$and $\mathrm{NO}_{2}{ }^{-}$are not or slightly contained in the fresh AC particles. It is therefore presumed that if the experiment of DNP decomposition is repeated using the same $\mathrm{TiO}_{2} / \mathrm{AC}-\mathrm{PET}$ film, the ions such as $\mathrm{NO}_{3}{ }^{-}, \mathrm{NO}_{2}{ }^{-}, \mathrm{CO}_{3}{ }^{2-}$ and $\mathrm{NH}_{4}{ }^{+}$adsorbed on $\mathrm{AC}$ particles affect the time courses of the concentrations of ions produced during the photocatalytic reaction.

Figure 4 shows the time courses of DNP and product ion concentrations in the treatment of an aqueous solution of DNP at an initial concentration of $54.5 \mathrm{mmol} \mathrm{m}^{-3}$ using a fresh $\mathrm{TiO}_{2} /$ AC-PET film (left figure; A) and a repeatedly used $\mathrm{TiO}_{2} / \mathrm{AC}-\mathrm{PET}$ 
film (right figure; B). As predicted from the experimental fact stated above, the $\mathrm{CO}_{3}{ }^{2-}$ concentration remarkably increased during the treatment because this ion was originally contained in AC particles and supposed to be released from them (Fig. 4 (A)). Since the AC particles on the $\mathrm{TiO}_{2} / \mathrm{AC}$-PET film were adhesively fixed onto one side of the PET film, the total amount of $\mathrm{CO}_{3}{ }^{2-}$ released is smaller than that released when AC particles were suspended in an aqueous solution. The $\mathrm{NH}_{4}{ }^{+}$concentration also increased. It is obvious that the time courses of these concentrations were influenced by the concentrations of ions produced by the DNP decomposition and originally contained in the AC particles. On the other hand, the fresh AC particles do not or slightly contain $\mathrm{NO}_{3}{ }^{-}$and $\mathrm{NO}_{2}{ }^{-}$. It is therefore presumed that most of these ions produced during the photocatalytic decomposition were adsorbed onto the AC particles. This makes it hard to quantitatively identify the time courses of product ion concentrations from the experimental data for fresh AC particles. The DNP concentration in Fig. 4 (B) decreased more slowly than did the experimental result in Fig. 4 (A), because repetitive use of the $\mathrm{TiO}_{2} /$ AC-PET film caused a drop in the adsorption capacity of AC. However, it decreased faster than did the $\mathrm{TiO}_{2}$-PET film. Because most of $\mathrm{CO}_{3}{ }^{2-}$ originally contained in the AC particles had already been solved out as a result of repetitive use of the $\mathrm{TiO}_{2} / \mathrm{AC}-\mathrm{PET}$ film, its concentration was not remarkably increased in this 
experimental run, although this time course data is also presumed to have been more or less influenced by adsorption of ions onto the $\mathrm{AC}$ particles. The $\mathrm{NO}_{3}^{-}$and $\mathrm{NO}_{2}^{-}$ concentrations were kept at almost zero values during the treatment of Fig. 4 (A), whereas they increased continuously or decreased to a zero value after increasing, as shown in Fig. 4 (B). The time course data evidently includes an influence of AC adsorption and therefore, it is impossible to conduct quantitative discussion. However, it is obvious that photocatalytic decomposition of DNP certainly occurred.

In a previous work [15], we found that the $\mathrm{TiO}_{2} / \mathrm{AC}-\mathrm{PET}$ film can treat an 1.8-times larger amount of DNP until AC is saturated with DNP than can do the AC-PET film. The $\mathrm{TiO}_{2} / \mathrm{AC}$-PET film also decreased the DNP concentration at an initial rate 2.86 times larger than that observed with the $\mathrm{TiO}_{2}$-PET film (compare Fig. 2 with Fig. 4). These results suggest that the DNP concentration at the $\mathrm{TiO}_{2}$ surface on the $\mathrm{TiO}_{2} / \mathrm{AC}-\mathrm{PET}$ film becomes higher because of rapid diffusion of DNP molecules, so that it decomposes DNP more rapidly than does the $\mathrm{TiO}_{2}$-PET film. As shown above, however, the present photocatalytic and adsorptive treatment is strongly influenced by the adsorption and desorption of product ions. It is thus difficult to experimentally elucidate the mechanism of the treatment. In the following, therefore, we will introduce a computer simulation methodology using mathematical models. 


\subsection{Investigation of reaction mechanisms based on mathematical models}

A $\mathrm{TiO}_{2}$-PET film was used to determine initial rates of decomposition of DNP at different initial concentrations. Aqueous DNP solutions were recirculated at a high linear velocity where the film-diffusional resistance can be neglected. In the treatment of aqueous solutions using a $\mathrm{TiO}_{2}$-PET film at linear velocity of $0.78 \mathrm{~m} \mathrm{~min}^{-1}$, the following linear relationship between $C_{\mathrm{b} 0} / v_{\mathrm{p} 0}$ and $C_{\mathrm{b} 0}$ was found under the assumption of Langmuir-Hinshelwood kinetics.

$$
\frac{C_{\mathrm{b} 0}}{v_{\mathrm{p} 0}}=158.7+0.864 C_{\mathrm{b} 0}
$$

The kinetic parameters were determined from the slope and intercept of this equation as $k_{\mathrm{p}}=350 \mathrm{mmol} \mathrm{m}^{-3} \mathrm{~min}^{-1}$ and $K_{\mathrm{H}}=0.0055 \mathrm{~m}^{3} \mathrm{mmol}^{-1}$. These values were inserted into Eq. (3) and this equation with $V_{\mathrm{L}}=5.0 \times 10^{-4} \mathrm{~m}^{3}$ was numerically solved to obtain the time course of DNP concentration. The calculated line is shown by a solid line in Fig. 5, where the experimental data were obtained from the decomposition of DNP at an initial concentration of $54.5 \mathrm{mmol} \mathrm{m} \mathrm{m}^{-3}$ using the $\mathrm{TiO}_{2}$-PET film at $u=0.78 \mathrm{~m} \mathrm{~min}^{-1}$. The calculated result is in a good agreement with the experimental data.

Figure 6 shows the time courses of DNP concentrations in the treatments of DNP solutions at various initial concentrations using the AC-PET film at $u=0.55 \mathrm{~m} \mathrm{~min}^{-1}$. 
Adsorption of organic compounds onto AC can usually be described by the Langmuir adsorption isotherm. In general, the adsorption reaches equilibrium after the passage of a sufficiently long time and the concentrations of organic compounds finally become constant. The equilibrium DNP concentrations $C_{\mathrm{b}, \mathrm{eq}}$ were obtained from Fig. 6 and plotted against the initial concentrations $C_{\mathrm{b} 0}$. Obviously there is a linear relationship between $C_{\mathrm{b}, \mathrm{eq}}$ and $C_{\mathrm{b} 0}$. The slope value of the straight line was calculated and applied to Eq. (8). This calculation with $V_{\mathrm{L}}=5.0 \times 10^{-4} \mathrm{~m}^{3}$ and $V_{\mathrm{a}}=2.5 \times 10^{-5} \mathrm{~m}^{3}$ provided -7.33 for $\lambda_{a}$. All the obtained values were further applied to Eq. (7) to calculate the time course of $C_{\mathrm{b}}$. In this case, the value of $k_{\mathrm{La}}$ was changed so that the calculated results were fitted to the time course data at different initial DNP concentrations in Fig. 6. Consequently, $k_{\mathrm{La}}$ was obtained as $4.90 \times 10^{-4} \mathrm{~m} \mathrm{~min}^{-1}$. The calculated results shown by solid lines in Fig. 6 are in good agreements with the experimental data.

Figure 7 shows the relationship between the initial rate of treatment and the linear velocity in the treatments of aqueous DNP solutions at an initial DNP concentration of $54.5 \mathrm{mmol} \mathrm{m}^{-3}$ using $\mathrm{TiO}_{2^{-}}$and AC-PET films. The initial rate for the AC-PET film greatly increased almost linearly with an increase of $u$. On the other hand, the initial rate for the $\mathrm{TiO}_{2}$-PET film increased slightly with an increase of $u$ in its small region and approached a constant rate at $u$ above $0.5 \mathrm{~m} \mathrm{~min}^{-1}$. Its initial rate is considerably 
small compared to the initial rate for the AC-PET film. It is therefore clear that the adsorptive treatment of DNP using the AC-PET film is more rapid than the photocatalytic treatment using the $\mathrm{TiO}_{2}$-PET film.

Figure 8 shows the plot of the mass-transfer coefficients, which were determined from the experimental data in Fig. 7 by the convergence method, against the linear velocities. In this calculation, the volume of the $\mathrm{TiO}_{2}$ thin film was set as $V_{\mathrm{p}}=1.66 \times 10^{-6}$ $\mathrm{m}^{3}$, which was calculated by setting the surface area of the $\mathrm{TiO}_{2}$ film as $A_{\mathrm{s}}=0.0166 \mathrm{~m}^{2}$ and its film thickness as $1 \times 10^{-4} \mathrm{~m}$ as a result of SEM observation of the $\mathrm{TiO}_{2}$ film. When $u$ is less than $0.75 \mathrm{~m} \mathrm{~min}^{-1}$, the mass-transfer coefficient for the AC-PET film, i.e., $k_{\mathrm{La}}$, is larger, while when $u$ is larger than $0.75 \mathrm{~m} \mathrm{~min}^{-1}$, the mass-transfer coefficient for the $\mathrm{TiO}_{2}$-PET film, i.e., $k_{\mathrm{Lp}}$, becomes larger. This is because in the treatment of DNP using the $\mathrm{TiO}_{2}$-PET film, the rate of photocatalytic decomposition of DNP is small relative to the rate of diffusion of DNP and the treatment system therefore becomes reaction-limited for a smaller value of the linear velocity. As a result of applying a least-square method to the plotted data in Fig. 8, the equation for the mass-transfer coefficient was determined as

$$
k_{\mathrm{Lp}}=0.000698 u^{1.39}
$$

for the $\mathrm{TiO}_{2}$-PET film and as 


$$
k_{\mathrm{La}}=0.000897 u^{0.842}
$$

for the AC-PET film.

Equation (14) was used to calculate the relationship of $u$ and $E_{f}$ in the treatments of aqueous DNP solutions at an initial concentration of $54.5 \mathrm{mmol} \mathrm{m} \mathrm{m}^{-3}$ using the $\mathrm{TiO}_{2}$-PET film. At $u$ below $0.3 \mathrm{~m} \mathrm{~min}^{-1}, E_{f}$ was smaller than 0.5 because the film-diffusional resistance was large. At $u$ larger than $1 \mathrm{~m} \mathrm{~min}^{-1}$, on the other hand, $E_{f}$ increased with an increase of $u$ and then exceeded 0.9 , implying that the system was reaction-limited.

Figure 9 shows the time course of DNP concentrations in the treatments of aqueous DNP solutions at various initial concentrations using the $\mathrm{TiO}_{2} / \mathrm{AC}-\mathrm{PET}$ film at $u=0.55 \mathrm{~m}$ $\min ^{-1}$. A comparison of these experimental data with those in Fig. 6 indicates that the DNP concentration for the $\mathrm{TiO}_{2} /$ AC-PET film is decreased more quickly than that for the AC-PET film. This is because a part of DNP molecules rapidly diffusing by means of the adsorption power of $\mathrm{AC}$ are photocatalytically decomposed on the $\mathrm{TiO}_{2}$ surface. Consequently, the DNP concentration in the neighbourhood of the PET film is more decreased, which subsequently causes an increase in the diffusion flux of DNP and a quicker decrease in the DNP concentration in the bulk solution. To construct a mathematical model that is best fitted to these experimental data, we firstly investigated the performance of the following differential equation where the rate of decrease in the 
DNP concentration in the bulk solution occurs only by the diffusion based on the concentration gradient generated by the adsorption power of AC.

$$
-V_{\mathrm{L}} \frac{\mathrm{d} C_{\mathrm{b}}}{\mathrm{d} t}=k_{\mathrm{La}} A_{\mathrm{s}}\left(C_{\mathrm{b}}-C_{\mathrm{a}} e^{\lambda \mathrm{a}}\right)
$$

This equation provides a maximum for the rate of diffusion when the second term on the right-hand side is zero. Unfortunately, every calculated line was found to locate above the corresponding time course data at different initial DNP concentrations in Fig. 90. This result suggests that the diffusion of DNP from the bulk solution to the support surface is not simply dependent on the adsorption power of AC. We therefore added an effect of the DNP concentration decreased by the photocatalytic decomposition to Eq. (20) (see Eq. (9)) and investigated the performance of this modified equation. The value of $\lambda_{\mathrm{p}}$ was changed so that the calculated results by Eqs. (9)-(11) were fitted to the experimental data in Fig. 10. As a result, we obtained -1.0 for $\lambda_{\mathrm{p}}$.

Figure 10 shows the simulation results by Eqs. (9)-(11) for the time courses of amounts of DNP adsorbed onto AC using an AC-PET film and photocatalytically decomposed using a $\mathrm{TiO}_{2}$ /AC-PET film the treatments of aqueous DNP solutions at an initial concentration of $54.5 \mathrm{mmol} \mathrm{m}^{-3}$ at $u=0.1$ and $0.55 \mathrm{~m} \mathrm{~min}^{-1}$. It is clear that $\mathrm{TiO}_{2}$ decomposes a half of DNP molecules at $u=0.1$ and three tens at $u=0.55 \mathrm{~m} \mathrm{~min}^{-1}$. The amount of DNP decomposed by $\mathrm{TiO}_{2}$ becomes larger when $u$ is smaller. This is because 
when $u$ is small, DNP diffuses more slowly, which increases a probability that DNP molecules are captured and decomposed by $\mathrm{TiO}_{2}$ before they are adsorbed onto AC. The photocatalytic decomposition of $\mathrm{DNP}_{\text {by }} \mathrm{TiO}_{2}$ would lower the burden of the adsorption of DNP onto $\mathrm{AC}$ on the $\mathrm{TiO}_{2} / \mathrm{AC}-\mathrm{PET}$ film. This explains the experimental result that the lifetime of $\mathrm{AC}$ on the $\mathrm{TiO}_{2} / \mathrm{AC}$-PET film was 1.8 times longer than that of $\mathrm{AC}$ on the AC-PET film [15]. From the findings that the calculated results shown by solid lines in Fig. 9 were in good agreements with the experimental data and the calculated result agreed with the experimental observation concerning the lifetime of $\mathrm{AC}$, it is obvious that the mathematical model constructed for the treatment of an aqueous DNP solution using the $\mathrm{TiO}_{2} / \mathrm{AC}$-PET film is reasonable.

Figure 11 compares the simulations for the treatments of aqueous DNP solutions at an initial concentration of $54.5 \mathrm{mmol} \mathrm{m}^{-3}$ using the $\mathrm{TiO}_{2} / \mathrm{AC}$ - and $\mathrm{TiO}_{2}$-PET films at $u=0.1$ and $0.5 \mathrm{~m} \mathrm{~min}^{-1}$. In both cases of linear velocities, the DNP concentrations in the bulk solution for the $\mathrm{TiO}_{2} / \mathrm{AC}$-PET film decrease more quickly than those for the $\mathrm{TiO}_{2}$-PET film. This characteristic is more pronounced as $u$ is smaller. The DNP concentration at the $\mathrm{TiO}_{2}$ thin film on the $\mathrm{TiO}_{2} / \mathrm{AC}$-PET film is large in the initial stage of the decomposition. This is because in the initial stage, a large amount of DNP molecules rapidly diffuse by means of the adsorption power of $\mathrm{AC}$, which leads to an 
increase in the DNP concentration not at the surface of but in the neighborhood of $\mathrm{TiO}_{2}$ thin film. This concentration thereafter decreases rapidly, then becomes smaller than the DNP concentration at the $\mathrm{TiO}_{2}$ film on the $\mathrm{TiO}_{2}$-PET film, and finally approaches a zero value. At a low linear velocity, the $\mathrm{DNP}$ concentration at the $\mathrm{TiO}_{2}$ film on the $\mathrm{TiO}_{2}$ /AC-PET film would initially become high compared to that at the $\mathrm{TiO}_{2}$ film on the $\mathrm{TiO}_{2}$-PET film. This suggests that when $u$ is small, the $\mathrm{TiO}_{2} /$ AC-PET photocatalytically decomposes a larger amount of DNP molecules than does the $\mathrm{TiO}_{2}$-PET film. This finding is useful for the wastewater treatment using $\mathrm{TiO}_{2}$ excited with sunlight because the use of a smaller linear velocity is advantageous for energy saving.

The experimental results indicate that the $\mathrm{TiO}_{2} / \mathrm{AC}$-PET film irradiated with UV light can efficiently decompose DNP because DNP diffuses quickly owing to the adsorption power of $\mathrm{AC}$ and its concentration increases in the very neighborhood of the support. When the film-diffusional resistance is large, the percentage of DNP molecules decomposed by $\mathrm{TiO}_{2}$ is increased compared to that adsorbed onto AC. There was no mathematical model simultaneously describing both the photocatalytic decomposition and $\mathrm{AC}$ adsorption under the condition where the $\mathrm{AC}$ surface is completely covered with a $\mathrm{TiO}_{2}$ film but the adsorption power of $\mathrm{AC}$ is not remarkably lost. The mathematical model constructed here simply expresses the increases in the DNP 
concentration at the surfaces of $\mathrm{AC}$ and $\mathrm{TiO}_{2}$, caused by the $\mathrm{AC}$ adsorption and photocatalytic decomposition of DNP, in terms of partition phenomena. Nevertheless, the calculated results indicate that the present model can successfully explain the treatment of an aqueous DNP solution using the $\mathrm{TiO}_{2} / \mathrm{AC}$-PET film.

\section{Conclusions}

In the first stage of the present work, we experimentally investigated the mechanism of the treatment of an aqueous DNP solution using $\mathrm{TiO}_{2^{-}}, \mathrm{AC}-$, and $\mathrm{TiO}_{2} / \mathrm{AC}-\mathrm{PET}$ films. As a result, the following conclusions are drawn.

1) Elimination of nitro groups from DNP occurs quickly.

2) Decomposition of intermediates produced from DNP into $\mathrm{CO}_{3}{ }^{2-}$ occurs slowly. Unfortunately, it was impossible to correctly measure the time courses of the concentrations of product ions because they were adsorbed onto or desorbed from AC particles. In the second stage, therefore, we performed computer simulations using mathematical models. As a result, the following conclusions are drawn.

3) In the treatment of an aqueous DNP solution at an initial concentration of $54.5 \mathrm{mmol}$ $\mathrm{m}^{-3}$ using the $\mathrm{TiO}_{2}$-PET film, the effectiveness factor takes a value more than 0.9 at a 
linear velocity above $1 \mathrm{~m} \mathrm{~min}^{-1}$ and the present system becomes reaction-limited.

4) In the treatment of an aqueous DNP solution using the $\mathrm{TiO}_{2} / \mathrm{AC}$-PET film, the diffusion of DNP from a bulk solution to a $\mathrm{TiO}_{2}$ film is based on the gradient of DNP concentration, generated as a result of the AC adsorption and photocatalytic decomposition of DNP, in the very neighborhood of $\mathrm{TiO}_{2}$ film.

5) This diffusion increases the DNP concentration at the surface of $\mathrm{TiO}_{2}$ film, thereby enhancing the rate of photocatalytic decomposition.

6) Moreover, the burden of the adsorption of DNP onto AC is lowered compared to its treatment using the AC-PET film because a part of DNP molecules are photocatalytically decomposed and the percentage of this decomposition is increased at a lower linear velocity.

7) The mathematical model taking into consideration a film-diffusional effect can successfully explain the complicated mechanism of the treatment of an aqueous DNP solution using the $\mathrm{TiO}_{2} / \mathrm{AC}-\mathrm{PET}$ film. 


\section{References}

[1] V. Kavitha, K. Palanivelu, Degradation of nitrophenols by Fenton and photo-Fenton process, J. Photochem. Photobio. A Chem., 170 (2005) 83-95.

[2] M. Ksibi, A. Zemzemi, R. Bouckchina, Photocatalytic degradability of substituted phenols over UV irradiated $\mathrm{TiO}_{2}$, J. Photochem. Photobiol. A Chem., 159 (2003) 61-70. [3] P.S. Mukherjee, A.K. Ray, Major challenges in the design of a large-scale photocatalytic reactor for water treatment, Chem. Eng. Technol., 22 (1999) 253-260. [4] K. Nakano, E. Obuchi, S. Takagi, R. Yamamot, T. Tanizaki, M. Taketomi, M. Eguchi, K. Ichida, S. M., A. Hashimoto, Photocatalytic treatment of water containing dinitrophenol and city water over TiO2/SiO2, Separ. Puri. Tech., 34 (2004) 67-72. [5] Ministry of the Environment of Japan PRTR data, http://www.env.go.jp/prtr/prtrinfo/contents/2007/html_jp/T1_2007992000.htm (2007). [6] J. Chen, D.F. Ollis, W.H. Rulkens, H. Bruning, Photocatalyzed oxidation of alcohols and organochlorides in the presence of native $\mathrm{TiO} 2$ and metallized $\mathrm{TiO} 2$ suspensions. Part (I): photocatlytic activity and pH influence, Wat. Res., 33 (1999) 661-668.

[7] M.T. Hoffmann, S.T. Martin, W. Choi, D.W. Bahnemann, Environmental applications of semiconductor photocatalysis, Chem. Rev., 95 (1995) 69-96.

[8] S. Fukinbara, F. Shiraishi, Characteristics of the photocatalytic reactor with an annular array of glass tubes surrounding a light source: 2.Kinetc analysis, CELSS J., 13 (2001) 11-23.

[9] S. Fukinbara, F. Shiraishi, K. Nakano, Characteristics of the photocatalytic reactor with an annular array of glass tubes surrounding a light source: 1 . Selection of a light source and photocatalyst support, CELSS J., 13 (2001) 1-10.

[10] I.J. Ochuma, R.P. Fishiwick, J. Wood, J.M. Winerbottom, Photocatalytic oxidation 
of 2, 4, 6-trichlorophenol in water using a concurrent downflow contactor reactor (CDCR), J. Hazard. Mater., 144 (2007).

[11] D.K. Lee, S.C. Kim, I.C. Cho, S.J. Kim, S.W. Kin, Photocatalytic oxidation of microcystin-LR in a fluidized bed reactor having $\mathrm{TiO}_{2}$-coated activated carbon, Sep. and Pur. Tech., 59-66 (2004).

[12] Y.J. Li, X.D. Li, J.W. Li, J. Yin, photocatalytic degradation of methyl orange by $\mathrm{TiO}_{2}$-coated activated carbon and kinetic study, Wat. Res., 40 (2006) 1119-1126.

[13] F. Shiraishi, T. Nomura, S. Yamaguchi, Y. Ohbuchi, Rapid removal of trace HCHO from indoor air by an air purifier consisting of a continuous concentrator and photocatalytic reactor and its computer simulation, Chem. Eng. J, 127 (2007) 157-165. [14] F. Shiraishi, S. Yamaguchi, Y. Ohbuchi, A rapid treatment of formaldehyde in a highly-tight room using a photocatalytic reactor combined with a continuous adsorption and desorption apparatus, Chem. Eng. Sci., 58 (2003) 929-934.

[15] X. Cao, Y. Oda, F. Shiraishi, Photocatalytic and adsorptive treatment of 2,4-dinitrophenol using a TiO2 film covering activated carbon surface, Chem. Eng. J, $156(2010) 98-105$.

[16] F. Shiraishi, S. Ikeda, N. Kamikariya, Photocatalytic decompositons of gaseous $\mathrm{HCHO}$ over thin films of anatase titanium oxide converted from amorphous in a heated air and in a aqueous solution of hydrogen peroxide, Chem. Eng. J, 148 (2009) 234-241. [17] F. Shiraishi, C. Kawanishi, Effect of diffusional film on formation of hydrogen peroxide in photocatalytic reaction, J. Phys. Chem. A, 108 (2004) 10491-10496.

[18] F. Shiraishi, M. Nagano, S.P. Wang, Characterization of a photocatalytic reaction in a continuous-flow recirculation reactor system, J. Tech. Biotech., 81 (2006) 1039-1048. [19] F. Shiraishi, T. Nakasako, Z.Z. Hua, Formation of hydrogen peroxide in 
photocatalytic reactions, J. Phys. Chem. A., 107 (2003) 11072-11081.

[20] S. Wang, F. Shiraishi, M. Nagano, Decompostion of formic acid in a photocatalytic reactor with a parallel array of four light sources, J. Chem. Tech. Biotech., 77 (2002) 805-810.

[21] S. Wang, F. Shiraishi, K. Nakano, A synergistic effect of photocatalysis and ozonation on decompostion of formic acid in an aqueous solution, Chem. Eng. J, 87 (2002) 261-271.

[22] S. Fukinbara, F. Shiraishi, H. Nagasue, A mathematical model for batch-recirculation reactor systems and its numerical calculation method, CELSS J., 12 (2000) 9-18.

[23] M.G. White, O. Bensalem, W.R. Ernst, The mathematical modeling of batch recirculation reactors for kinetics studies, Chem. Eng. J., 25 (1982) 223-227.

[24] F. Shiraishi, Computational methods for analysis of immobilized enzyme reactions: from reaction kinetics to reactor-design methods, Corona, Tokyo, 1997.

[25] F. Shiraishi, M. Hiromitsu, T. Hasegawa, S. Kasai, A computational method for determination of the mass-transfer coefficient in packed-bed immobilized enzyme reactors, J. Chem. Tech. Biotechnol., 66 (1996) 405-413.

[26] F. Shiraishi, K. Toyoda, H. Miyakawa, Decomposition of gaseous formaldehyde in a photocatalytic reactor with a parallel array of light sources 2. Reactor performance, Chem. Eng. J, 114 (2005) 148-151. 


\section{Legend}

Fig. 1 Schematic of a batch-recirculation flow system with an annular-flow reactor installed with a $\mathrm{TiO}_{2^{-}}, \mathrm{AC}-$, or $\mathrm{TiO}_{2} / \mathrm{AC}-\mathrm{PET}$ film.

Fig. 2 Time courses of DNP and product ion concentrations in treatment of an aqueous solution of DNP at an initial concentration of $57.6 \mathrm{mmol} \mathrm{m}^{-3}$ using a $\mathrm{TiO}_{2}$-PET film at a linear velocity of $0.55 \mathrm{~m} \mathrm{~min}^{-1}$.

Fig. 3 A reaction mechanism estimated for photocatalytic decomposition of DNP.

Fig. 4 Time courses of DNP and product ion concentrations in treatment of aqueous solutions of DNP at an initial concentration of $54.5 \mathrm{mmol} \mathrm{m}^{-3}$ at a linear velocity of 0.55 m $\min ^{-1}:$ A; fresh $\mathrm{TiO}_{2} /$ AC-PET film (A), B; a repeatedly used $\mathrm{TiO}_{2} / \mathrm{AC}-\mathrm{PET}$ film (B).

Fig. 5 A time course of DNP concentration in treatment of an aqueous DNP solution at an initial concentration of $54.5 \mathrm{mmol} \mathrm{m}^{-3}$ using a $\mathrm{TiO}_{2}$-PET film at a linear velocity of $0.78 \mathrm{~m} \mathrm{~min}^{-1}$. The calculated line by Eqs. (3) is shown by a solid line.

Fig. 6 Time courses of DNP concentrations in treatments of aqueous DNP concentrations at different initial concentrations using an AC-PET film at a linear velocity of $0.55 \mathrm{~m} \mathrm{~min}^{-1}$. The calculated lines by Eq. (7) are shown by solid lines.

Fig.7 Relationships of initial reaction rate and linear velocity in treatments of aqueous DNP solutions using a $\mathrm{TiO}_{2}$ - and AC-PET film at initial concentration of $54.5 \mathrm{mmol} \mathrm{m} \mathrm{m}^{-3}$. The calculated lines for the $\mathrm{TiO}_{2}$ - and AC-PET films are shown by broken and solid lines, respectively.

Fig.8 A relationships between mass-transfer coefficient and linear velocity in treatments of aqueous DNP solutions using a $\mathrm{TiO}_{2}$ - and AC-PET film at initial concentration of $54.5 \mathrm{mmol} \mathrm{m}^{-3}$. The calculated lines by Eq. (18) for the $\mathrm{TiO}_{2}-\mathrm{PET}$ film and by Eq. (19) for the AC-PET film are shown by broken and solid lines, respectively. 
Fig. 9 Time courses of DNP concentrations in treatments of aqueous DNP concentrations at different initial concentrations using a $\mathrm{TiO}_{2} / \mathrm{AC}-\mathrm{PET}$ film at a linear velocity of $0.75 \mathrm{~m} \mathrm{~min}^{-1}$. The calculated lines by Eqs. (9) to (11) are shown by solid lines.

Fig. 10 Simulations of time courses of amounts of DNP adsorbed onto AC using an AC-PET film and photocatalytically decomposed using a $\mathrm{TiO}_{2} / \mathrm{AC}-\mathrm{PET}$ film in treatments of aqueous DNP solutions at an initial concentration of $54.5 \mathrm{mmol} \mathrm{m}^{-3}$ at a linear velocity of $0.1 \mathrm{~m} \mathrm{~min}^{-1}$ (left) and $0.55 \mathrm{~m} \mathrm{~min}^{-1}$ (right).

Fig. 11 Comparisons of time courses of DNP concentration in bulk solutions (left column) and at a photocatalyst surface (right column) in treatments of DNP solutions at an initial concentration of $54.5 \mathrm{mmol} \mathrm{m}^{-3}$ using $\mathrm{TiO}_{2^{-}}$and $\mathrm{TiO}_{2} /$ AC-PET films at a linear velocity of $0.1 \mathrm{~m} \mathrm{~min}^{-1}$ (upper line) and $0.5 \mathrm{~m} \mathrm{~min}^{-1}$ (lower line). 

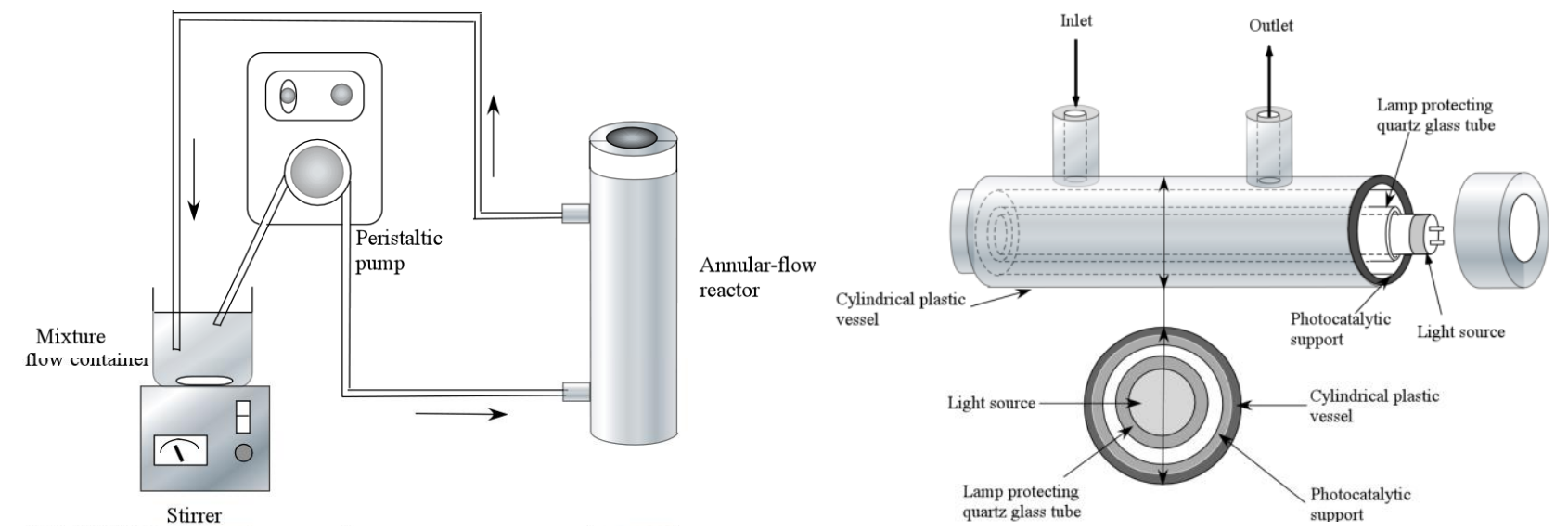

Fig. 1 Schematic of a batch-recirculation flow system with an annular-flow reactor installed with a $\mathrm{TiO}_{2-}, \mathrm{AC}-$, or $\mathrm{TiO}_{2} / \mathrm{AC}-\mathrm{PET}$ film. 


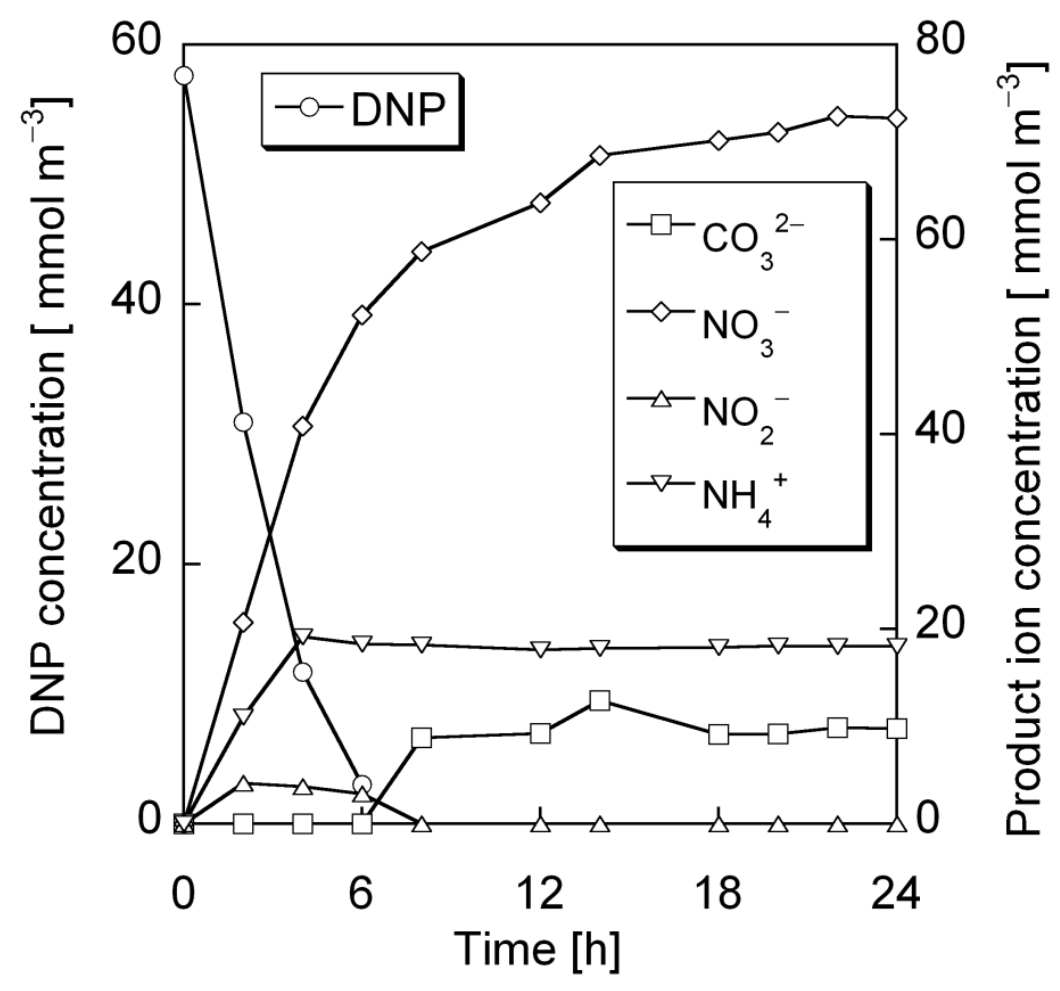

Fig. 2 Time courses of DNP and product ion concentrations in treatment of an aqueous solution of DNP at an initial concentration of $57.6 \mathrm{mmol} \mathrm{m}^{-3}$ using a $\mathrm{TiO}_{2}$-PET film at a linear velocity of $0.55 \mathrm{~m} \mathrm{~min}^{-1}$. 


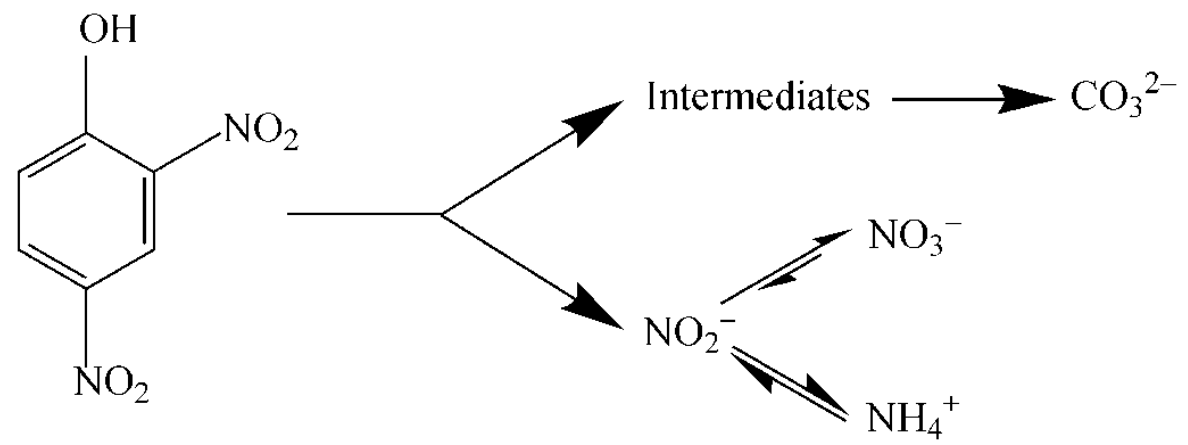

Fig. 3 A reaction mechanism estimated for photocatalytic decomposition of DNP. 

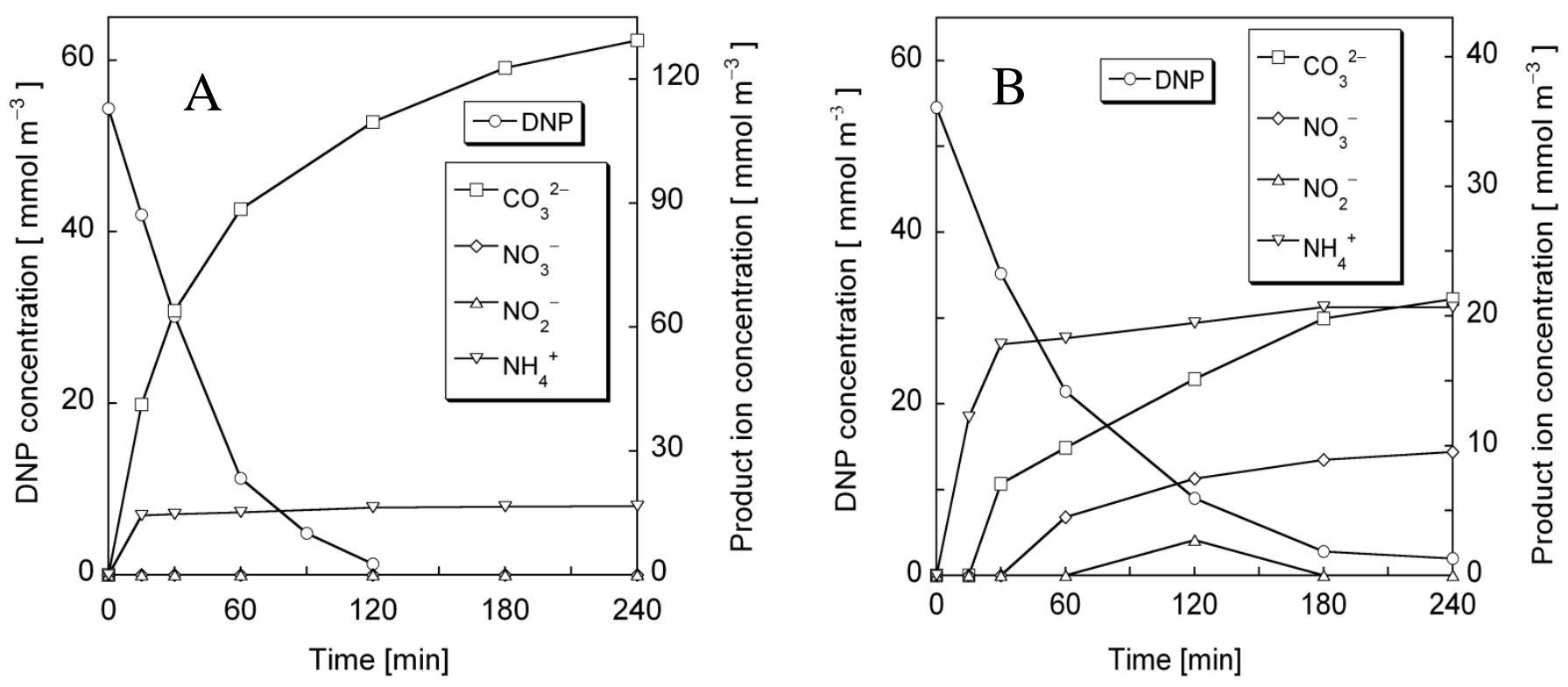

Fig. 4 Time courses of DNP and product ion concentrations in treatment of aqueous solutions of DNP at an initial concentration of $54.5 \mathrm{mmol} \mathrm{m}^{-3}$ at a linear velocity of 0.55 $\mathrm{m} \mathrm{min}{ }^{-1}$. Fresh $\mathrm{TiO}_{2} /$ AC-PET film; left (A), a repeatedly used $\mathrm{TiO}_{2} / \mathrm{AC}-\mathrm{PET}$ film; right (B). 


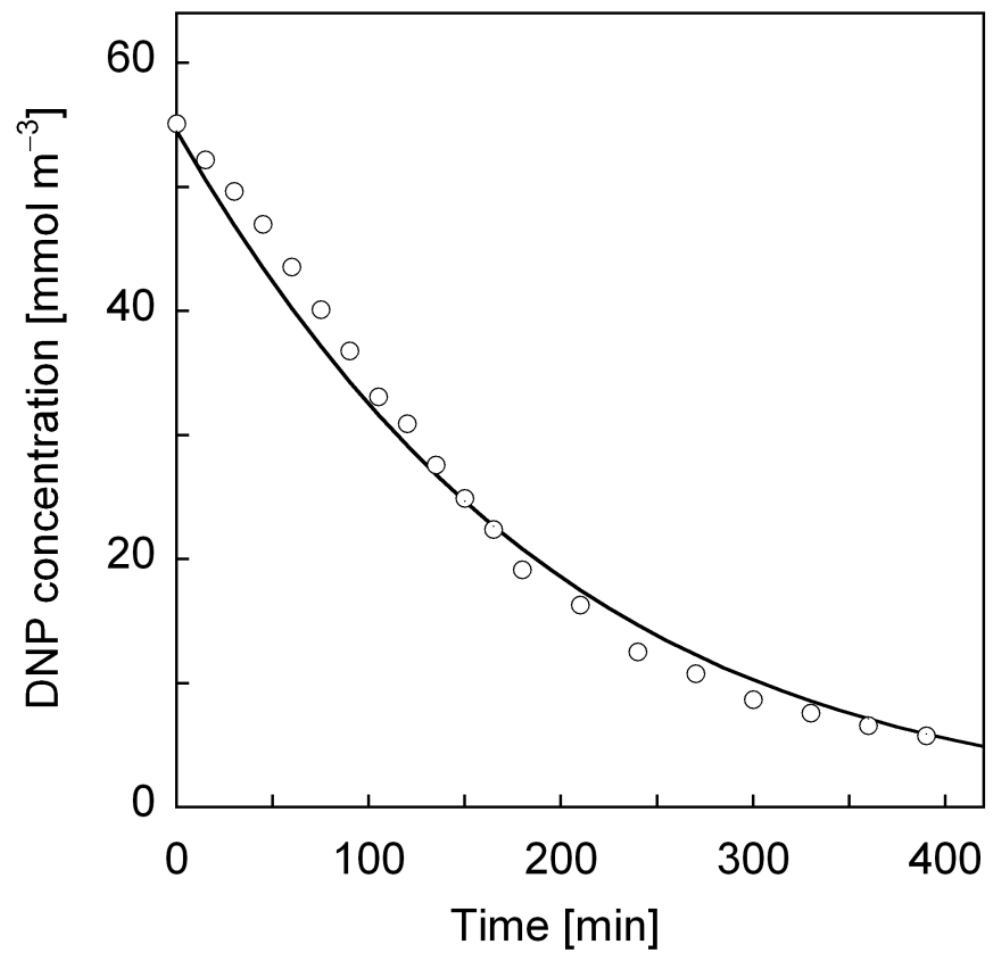

Fig. 5 A time course of DNP concentration in treatment of an aqueous DNP solution at an initial concentration of $54.5 \mathrm{mmol} \mathrm{m}^{-3}$ using a $\mathrm{TiO}_{2}$-PET film at a linear velocity of $0.78 \mathrm{~m} \mathrm{~min}^{-1}$. The calculated line by Eqs. (3) is shown by a solid line. 


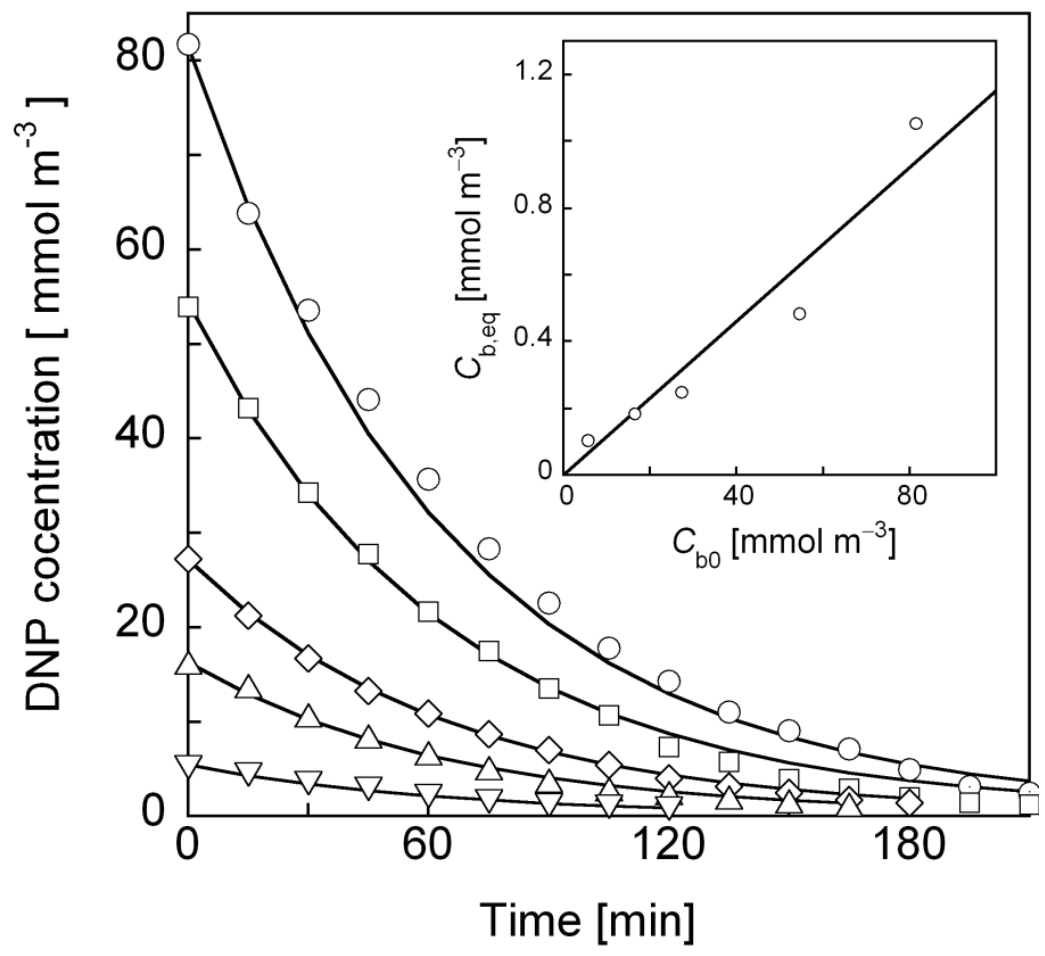

Fig. 6 Time courses of DNP concentrations in treatments of aqueous DNP concentrations at different initial concentrations using an AC-PET film at a linear velocity of $0.55 \mathrm{~m} \mathrm{~min}^{-1}$. The calculated lines by Eq. (7) are shown by solid lines. 


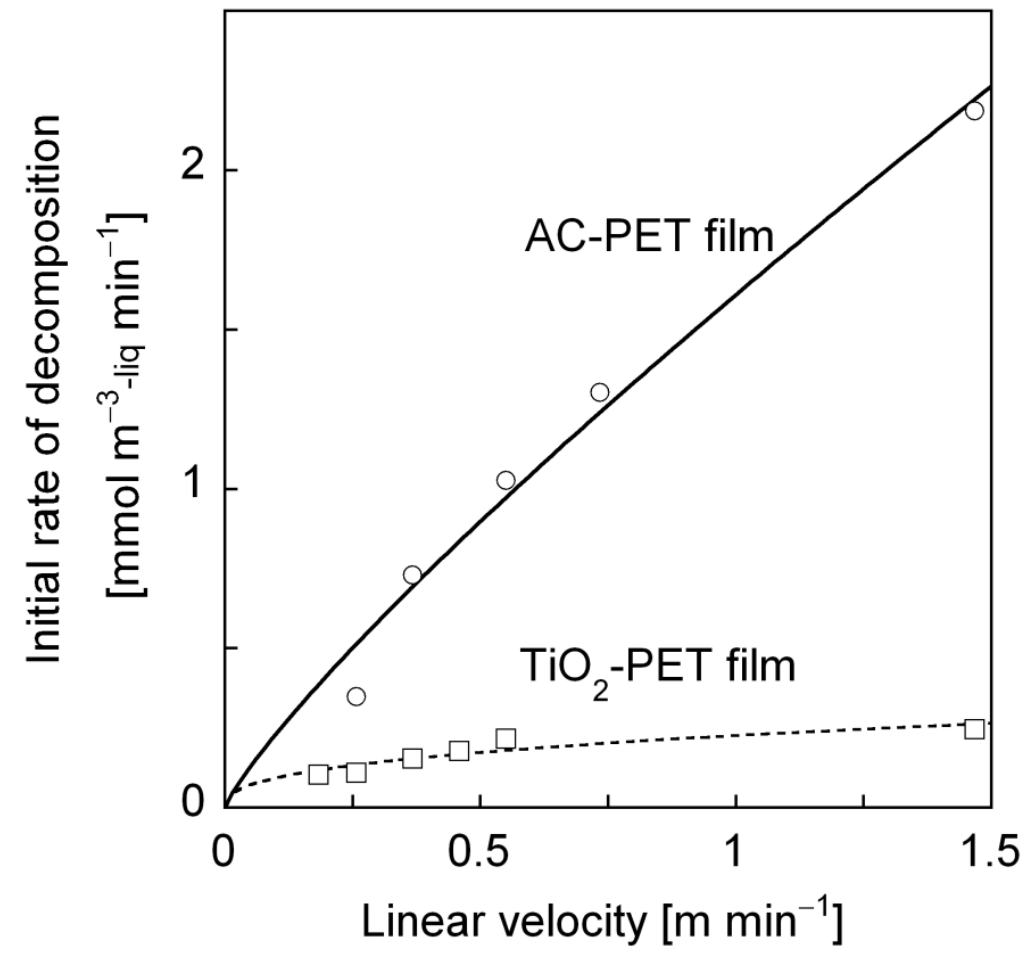

Fig. 7 Relationships of initial reaction rate and linear velocity in treatments of aqueous DNP solutions using a $\mathrm{TiO}_{2}$ - and AC-PET film at initial concentration of $54.5 \mathrm{mmol} \mathrm{m}^{-3}$. The calculated lines for the $\mathrm{TiO}_{2}$ - and AC-PET films are shown by broken and solid lines, respectively. 


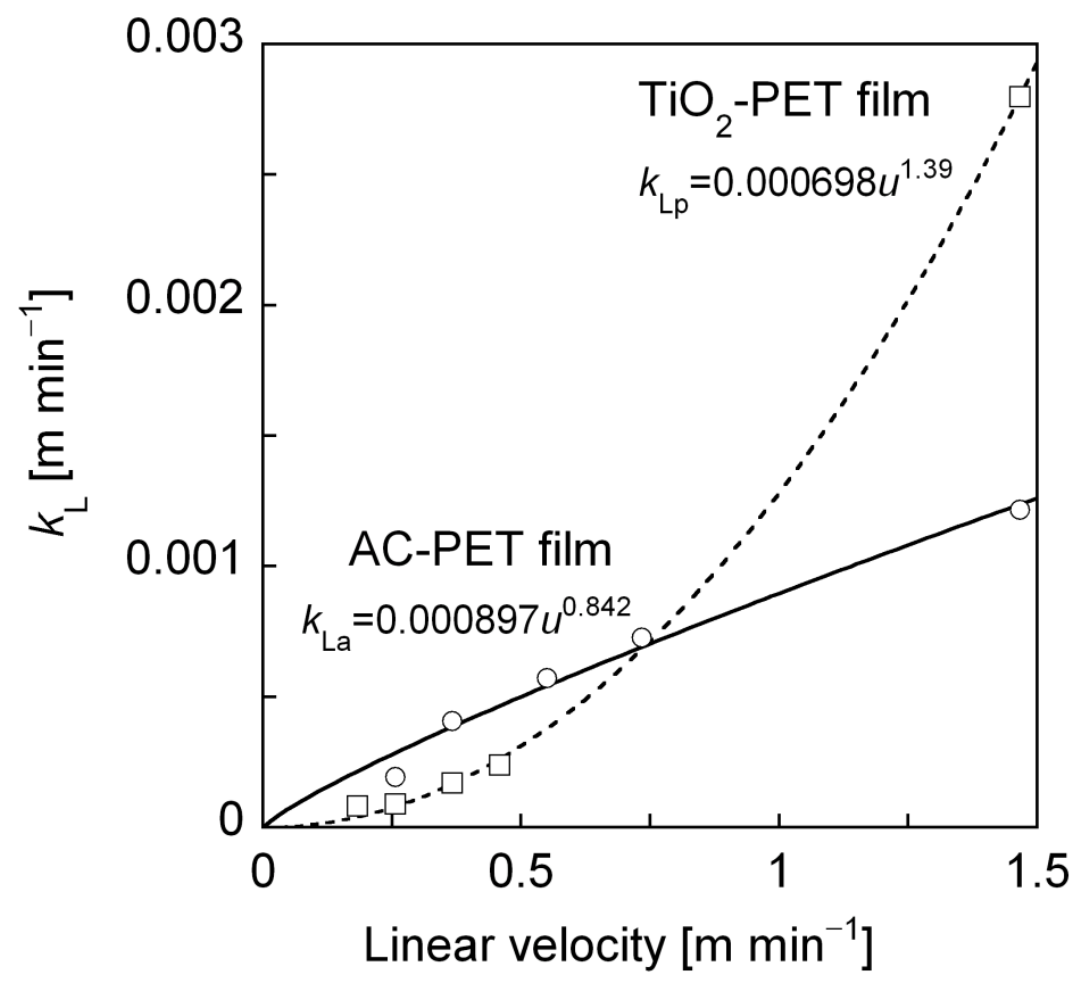

Fig.8 A relationships between mass-transfer coefficient and linear velocity in treatments of aqueous DNP solutions using a $\mathrm{TiO}_{2}$ - and AC-PET film at initial concentration of $54.5 \mathrm{mmol} \mathrm{m}^{-3}$. The calculated lines by Eq. (18) for the $\mathrm{TiO}_{2}-\mathrm{PET}$ film and by Eq. (19) for the AC-PET film are shown by broken and solid lines, respectively. 


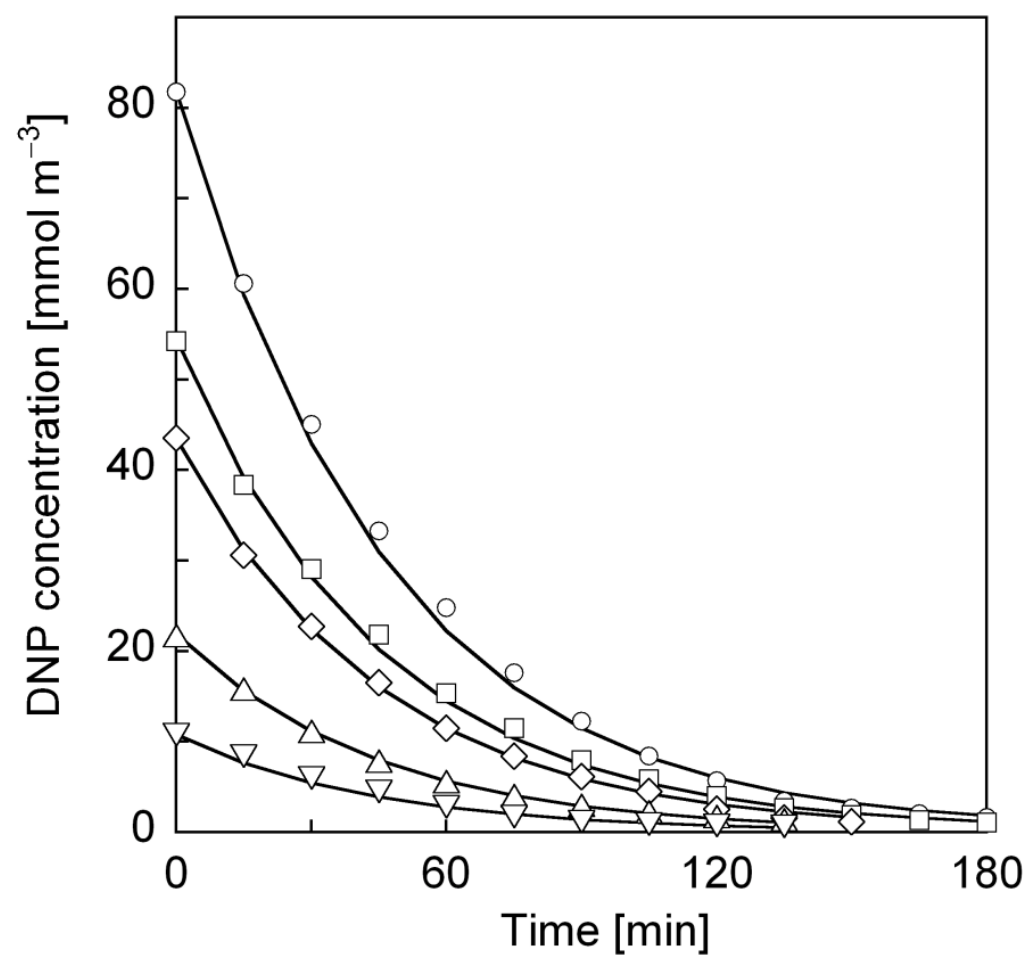

Fig. 9 Time courses of DNP concentrations in treatments of aqueous DNP concentrations at different initial concentrations using a $\mathrm{TiO}_{2} / \mathrm{AC}-\mathrm{PET}$ film at a linear velocity of $0.75 \mathrm{~m} \mathrm{~min}^{-1}$. The calculated lines by Eqs. (9) to (11) are shown by solid lines. 

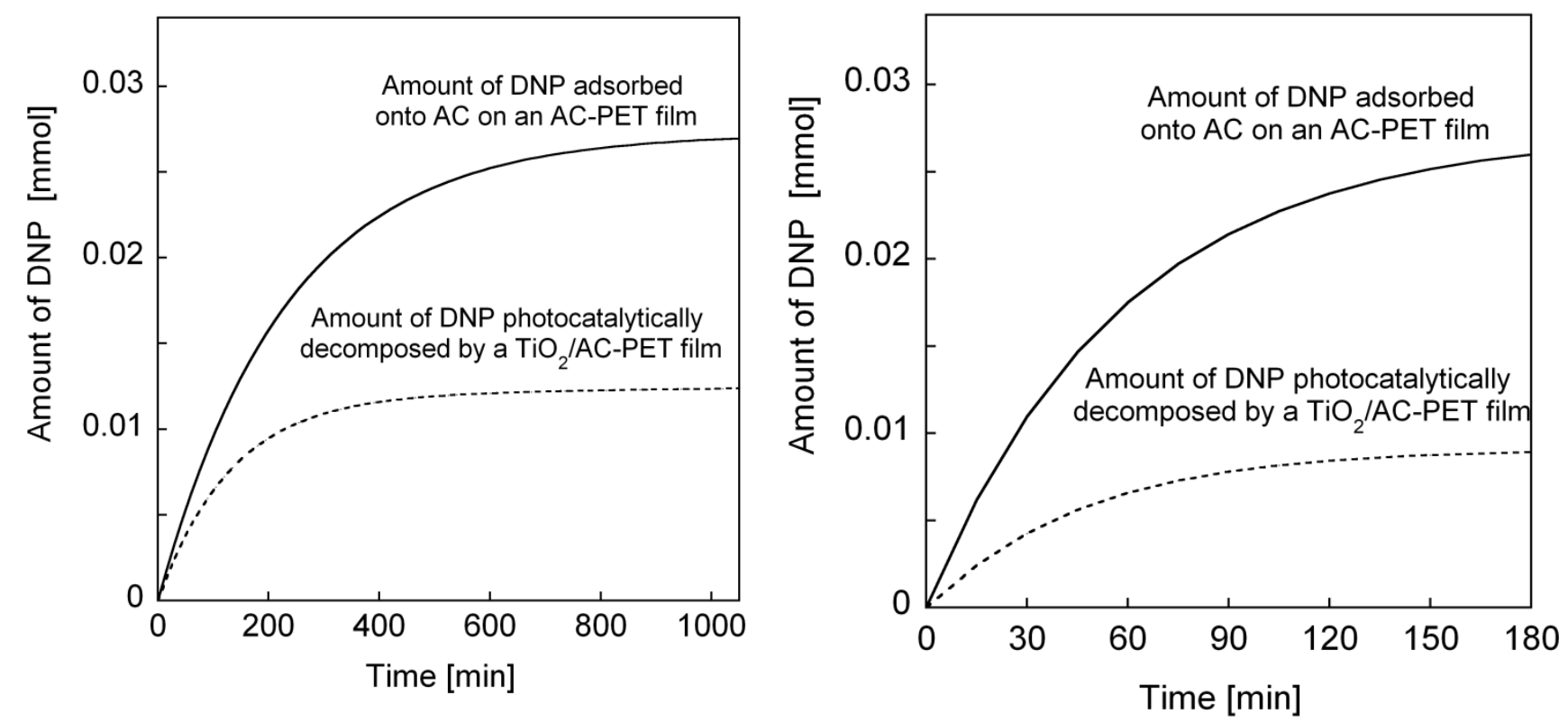

Fig. 10 Simulations of time courses of amounts of DNP adsorbed onto AC using an AC-PET film and photocatalytically decomposed using a $\mathrm{TiO}_{2} / \mathrm{AC}-\mathrm{PET}$ film in treatments of aqueous DNP solutions at an initial concentration of $54.5 \mathrm{mmol} \mathrm{m}^{-3}$ using an AC-PET film and $\mathrm{TiO}_{2} / \mathrm{AC}$-PET film at a linear velocity of $0.1 \mathrm{~m} \mathrm{~min}^{-1}$ (left) and $0.55 \mathrm{~m} \mathrm{~min}^{-1}$ (right). 

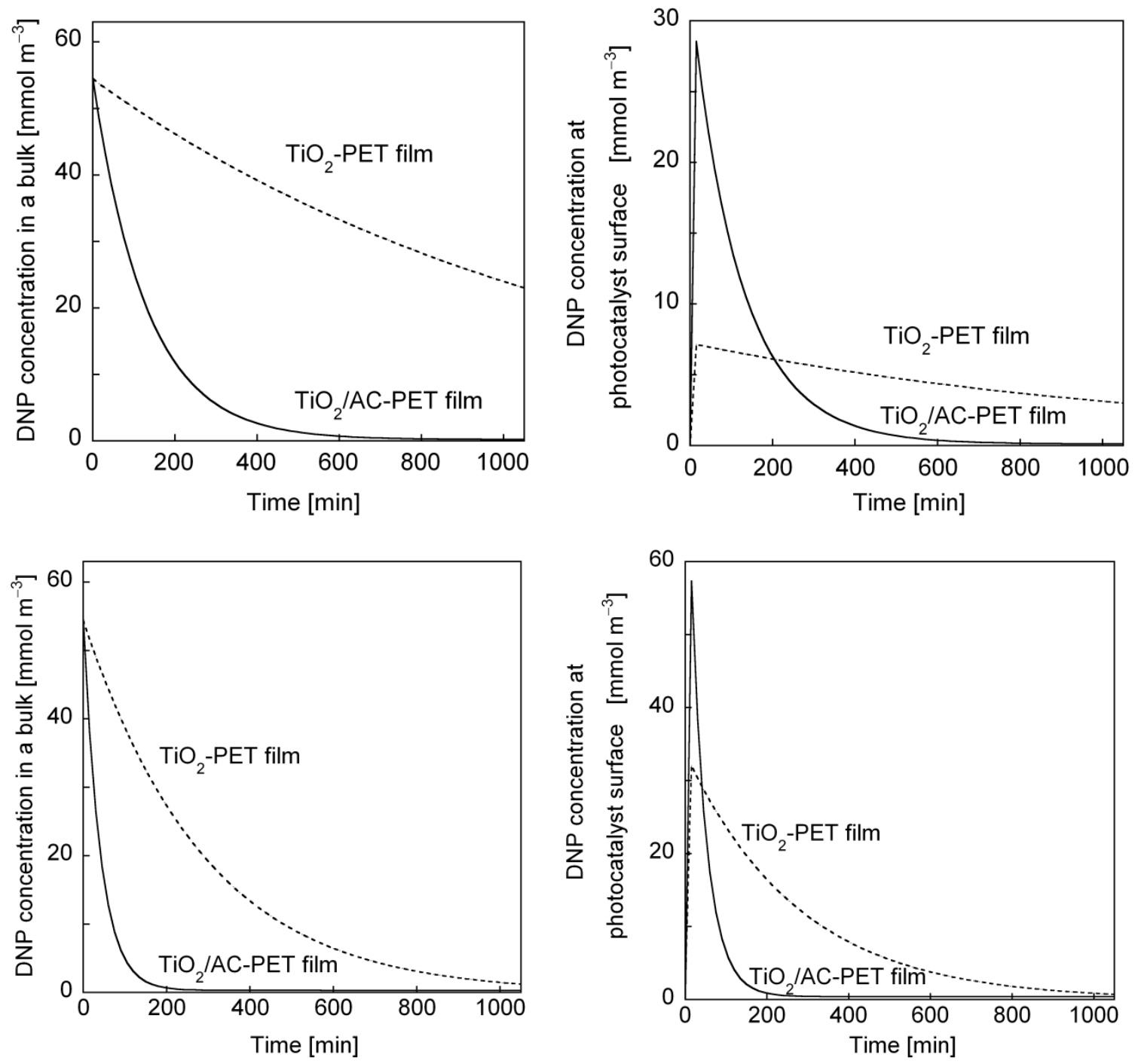

Fig. 11 Comparisons of time courses of DNP concentration in bulk solutions (left column) and at a photocatalyst surface (right column) in treatments of DNP solutions at an initial concentration of $54.5 \mathrm{mmol} \mathrm{m}^{-3}$ using $\mathrm{TiO}_{2^{-}}$and $\mathrm{TiO}_{2} / \mathrm{AC}$-PET films at a linear velocity of $0.1 \mathrm{~m} \mathrm{~min}^{-1}$ (upper line) and $0.5 \mathrm{~m} \mathrm{~min}^{-1}$ (lower line). 